\title{
Ethnic disparities in acquiring 2009 pandemic H1N1 influenza: a case-control study
}

\author{
Debeka Navaranjan ${ }^{1,2}$, Laura C Rosella ${ }^{1,2,3^{*}}$, Jeffrey C Kwong ${ }^{1,2,3,4}$, Michael Campitelli ${ }^{3}$ and Natasha Crowcroft ${ }^{1,2}$
}

\begin{abstract}
Background: Novel risk factors were associated with the 2009 pandemic A/H1N1 virus (pH1N1). Ethnicity was among these risk factors. Ethnic disparities in hospitalization and death due to $\mathrm{pH} 1 \mathrm{~N} 1$ were noted. The purpose of this study is to determine whether there are ethnic disparities in acquiring the 2009 pandemic H1N1.

Methods: We conducted a test-negative case-control study of the risk of pH1N1 infection using data from Ontario, Canada. Cases were laboratory confirmed to have influenza using reverse-transcriptase polymerase chain reaction (RT-PCR), and controls were obtained from the same population and were RT-PCR negative. Multivariate logistic regression was used to determine the association between ethnicity and pH1N1 infection, while adjusting for demographic, clinical and ecological covariates.

Results: Adult cases were more likely than controls to be self-classified as East/Southeast Asian (OR $=2.59,95 \% \mathrm{Cl}$ 1.02-6.57), South Asian ( $\mathrm{OR}=6.22,95 \% \mathrm{Cl} 2.01-19.24)$ and Black ( $\mathrm{OR}=9.72,95 \% \mathrm{Cl}$ 2.29-41.27). Pediatric cases were more likely to be self-identified as Black $(\mathrm{OR}=6.43,95 \% \mathrm{Cl} 1.83-22.59)$. However, pediatric cases without risk factors for severe influenza infection were more likely to be South Asian (OR 2.92, 95\% Cl 1.11-7.68), Black (OR 16.02, 95\% Cl 2.85-89.92), and West Asian/Arab, Latin American or Multi-racial groups (OR 3.09 95\% Cl 1.06-9.00).
\end{abstract}

Conclusions: pH1N1 cases were more likely to come from certain ethnic groups compared to test-negative controls. Insights into whether these disparities arise due to social or biological factors are needed in order to understand what approaches can be taken to reduce the burden of a future influenza pandemic.

Keywords: Influenza, Ethnicity, Epidemiology

\section{Background}

Canada's proportion of visible minorities has been increasing [1]. In 2006, $16.2 \%$ of Canada's population was comprised of visible minorities, a rise from $13.4 \%$ in 2001 and $11.2 \%$ in 1996. Ontario has the largest proportion of visible ethnic minorities in Canada. Given the rise in visible minorities, it is imperative to consider ethnic differences in health in order to address potential disparities. In Canada, ethnic disparities have been identified for chronic diseases such as cardiovascular disease, diabetes, and obesity [2-4]. However, the relationship with infectious diseases, including influenza, is less clear.

\footnotetext{
* Correspondence: laura.rosella@oahpp.ca

'Department of Public Health Sciences, Public Health Ontario, 480 University Avenue, Suite 300, Toronto, Ontario M5G 1 V2, Canada

${ }^{2}$ Dalla Lana School of Public Health, University of Toronto, 155 College Street, Toronto, Ontario M5T 3 M7, Canada

Full list of author information is available at the end of the article
}

There have been socio-economic disparities described for influenza. A study from the United States found that pediatric influenza-associated hospitalization was three times higher among high-poverty and high-crowding census tracts than in low-poverty and low-crowding census tracts [5]. Following the $2009 \mathrm{H} 1 \mathrm{~N} 1$ pandemic, disparities associated with acquisition and severity of the 2009 pandemic $\mathrm{A} / \mathrm{H} 1 \mathrm{~N} 1$ virus (pH1N1) were explored. A Canadian study exploring the relationship between social determinants of health and severity of $\mathrm{pH} 1 \mathrm{~N} 1$ found that hospitalization due to pH1N1 illness was associated with low education and living in neighbourhoods with high total or material deprivation [6]. Similarly, a study from England found that individuals from the most deprived quintile of the population had mortality rates due to $\mathrm{pH} 1 \mathrm{~N} 1$ three times greater than individuals from the least deprived quintile [7]. Studies from the United States have demonstrated ethnic disparities in incidence of influenza-like
Ciomed Central

(c) 2014 Navaranjan et al.; licensee BioMed Central Ltd. This is an Open Access article distributed under the terms of the Creative Commons Attribution License (http://creativecommons.org/licenses/by/2.0), which permits unrestricted use, distribution, and reproduction in any medium, provided the original work is properly credited. 
illness (ILI) during the $2009 \mathrm{H} 1 \mathrm{~N} 1$ pandemic [8] and risk of hospitalization due to pH1N1 [9-11]. In the Canadian context, the frequency and severity of illness from $\mathrm{pH} 1 \mathrm{~N} 1$ were higher among First Nations individuals compared to the rest of the population [12-14]. However, few studies in Canada have examined the risk of acquiring pH1N1 among other ethnic minorities, where the distribution of ethnic minorities in Canada is different compared to other countries.

Clinically, groups at risk for infections, complications, hospitalization, and/or death due to influenza have been identified as children, elderly, and individuals with certain chronic medical conditions [15]. Social factors could also play a role in shaping risk groups for influenza. For example, ease of access to medical care, ability to limit risk of acquiring illness through social distancing practices, and acceptance of protective practices such as immunization can shape the groups at greater risk of acquiring influenza $[16,17]$. Currently, no ethnic groups are recognized as being at high risk for infections or subsequent complications due to seasonal influenza.

In this study we used a laboratory confirmed testnegative case-control study conducted during the pandemic to investigate the association between ethnicity and risk of acquiring pandemic $\mathrm{H} 1 \mathrm{~N} 1$.

\section{Methods}

\section{Study design and population}

We conducted a test-negative case-control study, which bases case status on laboratory confirmation of $\mathrm{pH} 1 \mathrm{~N} 1$ and controls on the same test being negative [18]. Our population was a clinic-based sample, consisting of individuals presenting to clinics for medical care. We collected information on symptoms at the time of testing to restrict our sample to those presenting with influenza-like illness, defined as an acute onset of respiratory illness with fever, cough and with one or more of the following: sore throat, arthralgia, myalgia, or prostration which is likely due to influenza. Ontario residents of all ages who had nasopharyngeal swabs for pH1N1 by real-time reverse-transcriptase polymerase chain reaction (RT-PCR) were eligible for inclusion. We identified study participants as having confirmed pH1N1 through testing at the Public Health Ontario (PHO) Laboratory or Mount Sinai Hospital/University Health Network. The PHO laboratory conducted 100\% of the testing in the first months of the pandemic. Later on, a few other laboratories in major centres, the largest being Mount Sinai Hospital/University Health Network, conducted testing as well.

We included individuals with a test date between April 13, 2009 and July 20, 2009 (pandemic wave 1). The study was approved by the Research Ethics Board of University of Toronto, Toronto, Ontario, Canada.

\section{Study variables}

Trained interviewers from the Institute for Social Research at York University, Toronto conducted standardized telephone interviews between August and September 2009 to obtain information on demographics, health status, symptoms, and treatment, including hospitalization. For children 14 and under, interviews were completed by a parental proxy.

Individuals were asked to self-identify with an ethnicity/ ethnicities. Ethnicity was based on the question, "People in Canada come from many different ethnic and racial backgrounds. I would like you to identify which ethnicity best describes you. You may choose more than one category." Ethnicities were then read aloud to the participants. The ethnic groupings were based on the categories similar to Statistics Canada definitions: White, East/ Southeast Asian, South Asian, Black, West Asian/Arab, Latin American, and Other. Individuals who identified with multiple ethnic groups were classified as Multi-Racial person. West Asian/Arab, Latin American and Multi-racial were combined with Other because of small sample sizes for these ethnic groups. Aboriginals could not be included in this analysis because of lack of data ( $<1 \%$ of the sample).

Conceptual models of the association between ethnicity and acquisition of pH1N1 were developed a priori to guide the model building. This enabled the consideration of potential confounders and effect modifiers. The variables considered for adults were age, gender, current smoking status, number of visits to their regular primary care doctor in the prior 12 months (low, $\leq 1$; moderate, 2-6; high, >6), completion of post-secondary education, immigrant status (non-immigrant, $0-5$ years in Canada, $>5$ years in Canada), whether there were children in the household, household density (the ratio of the number of individuals in a household to the number of sleeping rooms), previous seasonal influenza vaccination, residence in Toronto (the capital and largest metropolitan city in Ontario), healthcare worker status, and testing date before or after June 11th, 2009 (the date when clinicians in Ontario were instructed to switch from submitting samples from all patients presenting with influenza-like illness to only submitting samples from patients at high risk of complications or for clinical management of hospitalized cases) [19]. In addition to the individual level variables collected through the survey, we examined the impact of deprivation captured through the Deprivation Index (DI) developed by Institut national de santé publique du Québec (INSPQ) [6,20,21]. The DI includes social deprivation, material deprivation, total deprivation, employment rate, proportion of the population with less than high school education, and prevalence with low income, where individuals were classified as living in an area with a high prevalence of low income if they resided in dissemination areas that were in the top quintile for low income of the population study. We also considered 
if individuals were tested in Toronto since this represents the major urban centre of our study population as well as contains the highest proportion of visible minorities and other ethnic groups. Underlying medical conditions were analyzed as a binary variable ( $\geq 1$ underlying medical conditions, which included diabetes, cancer, heart disease, asthma, chronic obstructive pulmonary disease (COPD), immune disorder, liver disease, kidney or renal disease, splenectomy, sickle cell anemia, seizure disorder, leukemia, cystic fibrosis, cerebral palsy), and obesity was considered separately. In children, all the same variables were considered, with underlying medical conditions restricted to those commonly observed in children ( $\geq 1$ of either asthma or immune disorder).

\section{Statistical analysis}

We first tested the interaction between ethnicity and being a child ( $<18$ years of age) in order to determine if appropriate to pool adults and children. Given the significant interaction and the different confounders, we then had to stratify all analysis according $<18$ years of age versus $\geq 18$ years of age. Descriptive statistics (means and proportions) were calculated for all variables. In order to develop the multivariable model, the Hosmer and Lemeshow forward model building strategy was used [22]. Briefly, odds ratios were obtained from univariate logistic regression to identify risk factors for acquisition of pH1N1. Variables were then entered into the model based on their effect size and p-value. Variables that had p-values $<0.05$ were included in the final model, as well as variables that had a significant $(>10 \%)$ effect on any of the ethnic group's OR. Age and gender were forced into the multivariate model, as these were deemed important variables to consider for the association. Gender was a priori identified as an important effect modifier and therefore the interaction was tested. At the end of this iterative model building process, a verification step was performed by adding any variable not selected for the original multivariate model one at a time to identify variables that, by themselves, were not influential but may have made an important contribution in the presence of other variables.

In addition, the following sensitivity analyses were performed: including individuals who were tested because of recent travel to Mexico; including individuals who did not present with symptoms at testing; no restrictions implemented (no exclusions); stratifying by presence of risk factors; stratifying by testing prior to June 11th, 2009; and according to Toronto residence.

\section{Results}

A total of 402 adults and 352 children were included. There were 229 controls and 173 cases among adults, and 112 controls and 240 cases among children. The demographic, clinical, and ecologic-level characteristics are described in Table 1. Among cases, more than half were females and $59 \%$ of adult cases and $40 \%$ of pediatric cases were of white ethnicity.

In adults, cases were more likely than controls to be South Asian (OR 3.07, 95\% CI 1.42-6.63) or Black (OR 4.50, 95\% CI 1.57-12.87), have greater than moderate material deprivation (4th quintile) (OR 2.11, 95\% CI 1.08-4.11), have children in the household (OR 1.70, 95\% CI 1.13-2.53), or be a recent immigrant (2.40, 95\% CI 1.01-5.68) (Table 2).

Among children, cases were more likely than controls to be East/Southeast Asian (OR 2.39, 95\% CI 1.14-5.01), Black (OR 4.38, 95\% CI 1.62-11.84) and either Latin American, West Asian/Arab or Multi-racial ethnicity (OR 2.84, 95\% CI 1.33-6.08), be from a neighbourhood with a high proportion of individuals with low income (OR 2.60, 95\% 1.36-4.96), have obtained the 2008 seasonal vaccine (OR 1.96, 95\% 1.16-3.31), or be an immigrant (OR 2.52, 95\% CI 1.02-6.25).

In multivariate analysis, adjusting for all significant confounders identified through our model building strategy increased the observed ORs for all ethnic groups (Table 3). After adjustment, for adults, cases were more likely to be East/Southeast Asian (OR 2.59, 95\% CI 1.02-6.57), South Asian (OR 6.22, 95\% CI 2.01-19.24), and Black (OR 9.72, 95\% CI 2.29-41.27). The sensitivity analyses indicate that including individuals who had travelled to Mexico increased the estimates for all ethnic groups. In addition, the analysis was conducted without any restrictions and this resulted in a slight increase in ORs for East/Southeast Asian (OR 2.96, 95\% CI 1.24-7.05), South Asian (OR 7.42, 95\% CI 2.79-19.74), and Black (OR 11.28, 95\% CI 2.85-44.60). Among those who did not have risk factors, the point estimates for the odds ratio after adjustment increased for South Asians; the confidence intervals for these estimates were wider given the reduced samples size after stratifying. As noted, the risk of diabetes and heart disease differs by ethnicity, hence, these medical conditions were considered separately as a group in the same analysis, and they did not appreciably change the effect sizes.

In multivariate analysis for children, cases were more likely to be Black (OR 6.43, 95\% CI 1.83-22.59) (Table 3). Adjusting for confounders increased the observed OR for Black ethnicity. When the analysis included individuals who did not have symptoms at time of testing, the estimates did not change for any ethnicity except for the Black group (OR 5.44, 95\% CI 1.71-17.24). For the analysis conducted without any restrictions (no exclusions), the estimates did not change appreciably. When stratifying by presence of risk factors, among those without risk factors, the estimates increased for all ethnic groups, but the greatest change was observed for the Black group. 
Table 1 Characteristics of the adult and pediatric study population by case status

\begin{tabular}{|c|c|c|c|c|c|c|c|c|c|c|c|c|c|}
\hline \multirow[b]{3}{*}{ Variable } & & \multicolumn{6}{|c|}{ Adults } & \multicolumn{6}{|c|}{ Children } \\
\hline & & \multicolumn{2}{|c|}{$\begin{array}{c}\text { Total study } \\
\text { population } \\
(\mathrm{N}=402)\end{array}$} & \multicolumn{2}{|c|}{$\begin{array}{c}\text { Tested } \\
\text { negative } \\
(\mathrm{N}=229)\end{array}$} & \multicolumn{2}{|c|}{$\begin{array}{c}\text { Tested } \\
\text { positive } \\
(\mathrm{N}=173)\end{array}$} & \multicolumn{2}{|c|}{$\begin{array}{c}\text { Total study } \\
\text { population } \\
(\mathrm{N}=352)\end{array}$} & \multicolumn{2}{|c|}{$\begin{array}{c}\text { Tested } \\
\text { negative } \\
(\mathrm{N}=112)\end{array}$} & \multicolumn{2}{|c|}{$\begin{array}{c}\text { Tested } \\
\text { positive } \\
(\mathrm{N}=240)\end{array}$} \\
\hline & & $\mathrm{N}$ & $\overline{\%}$ & $\mathbf{N}$ & $\overline{\%}$ & $\mathrm{~N}$ & $\overline{\%}$ & $\mathbf{N}$ & $\overline{\%}$ & $\mathrm{~N}$ & $\overline{\%}$ & $\mathbf{N}$ & $\%$ \\
\hline \multicolumn{14}{|c|}{ Ethnicity* } \\
\hline & White & 266 & 66.2 & 164 & 71.6 & 102 & 59.0 & 166 & 47.2 & 70 & 62.5 & 96 & 40.0 \\
\hline & East/Southeast Asian & 42 & 10.5 & 23 & 10.0 & 19 & 11.0 & 47 & 13.4 & 11 & 9.8 & 36 & 15.0 \\
\hline & South Asian & 32 & 8.0 & 11 & 4.8 & 21 & 12.1 & 47 & 13.4 & 14 & 12.5 & 33 & 13.8 \\
\hline & Black & 19 & 4.7 & 5 & 2.2 & 14 & 8.1 & 35 & 9.9 & 5 & 4.5 & 30 & 12.5 \\
\hline & Other & 35 & 8.7 & 20 & 8.7 & 15 & 8.7 & 49 & 13.9 & 10 & 8.9 & 39 & 16.3 \\
\hline
\end{tabular}

Age

Gender (female)

BMI class

Overweight $(25 \leq \mathrm{BMl}<30)$

Obese $(\mathrm{BMI} \geq 30)$

Current smoker

$\begin{array}{rrrr}<5 & \text { N/A } & & \text { N/A } \\ 5-11 & \text { N/A } & & \text { N/A } \\ 12-17 & \text { N/A } & & \text { N/A } \\ 18-34 & 150 & 37.3 & \\ 35-49 & 124 & 30.9 \\ 50-64 & 95 & 23.6 \\ 65+ & 33 & 8.2\end{array}$

$241 \quad 60.0 \quad 139$

.

$$
187
$$

114

\section{Current smoker}

Missing

$$
\text { Missing }
$$

72
110
N/A$$
46.5 \quad 111
$$$$
\begin{array}{ll}
46.5 & 111 \\
28.4 & 62
\end{array}
$$

N/A

N/A

N/A

N/A
N/A
N/A

N/A
N/A
N/A

31.0

53

37

41.0
30.6
21.4

94

$\begin{array}{lll}135 & 38.4 & 31\end{array}$

$123 \quad 34.9 \quad 36$

N/A

N/A

N/A

9.2

12

60.7

102

6.9

N/A

$246 \quad 69.9$

N/A

N/A

N/A

N/A

$\begin{array}{lll}40.2 & 49 & 20.4\end{array}$

\begin{tabular}{|c|c|c|c|c|c|c|c|c|c|c|c|c|c|}
\hline & $<1$ & 73 & 18.2 & 45 & 19.7 & 28 & 16.2 & 78 & 22.2 & 20 & 17.9 & 58 & 24.2 \\
\hline & 2 to 6 & 257 & 63.9 & 152 & 66.4 & 105 & 60.7 & 200 & 56.8 & 68 & 60.7 & 132 & 55.0 \\
\hline & $>6$ & 72 & 17.9 & 32 & 14.0 & 40 & 23.1 & 74 & 21.0 & 24 & 21.4 & 50 & 20.8 \\
\hline Underlying medical conditions & & 86 & 21.4 & 42 & 18.3 & 44 & 25.4 & 56 & 15.9 & 20 & 17.9 & 36 & 15.0 \\
\hline \multicolumn{14}{|l|}{ Material deprivation $^{\neq}$} \\
\hline & 1 (low) & 95 & 23.6 & 63 & 27.5 & 32 & 18.5 & 71 & 20.2 & 26 & 23.2 & 45 & 18.8 \\
\hline & 2 & 87 & 21.6 & 46 & 20.1 & 41 & 23.7 & 74 & 21.0 & 26 & 23.2 & 48 & 20.0 \\
\hline & 3 & 65 & 16.2 & 37 & 16.2 & 28 & 16.2 & 67 & 19.0 & 23 & 20.5 & 44 & 18.3 \\
\hline & 4 & 58 & 14.4 & 28 & 12.2 & 30 & 17.3 & 70 & 19.9 & 19 & 17.0 & 51 & 21.3 \\
\hline & 5 (high) & 73 & 18.2 & 45 & 19.7 & 28 & 16.2 & 56 & 15.9 & 18 & 16.1 & 38 & 15.8 \\
\hline \multicolumn{14}{|l|}{ Social deprivation ${ }^{\ddagger}$} \\
\hline & 1 (low) & 84 & 20.9 & 47 & 20.5 & 37 & 21.4 & 105 & 29.4 & 37 & 33.0 & 68 & 28.3 \\
\hline & 2 & 69 & 17.2 & 35 & 15.3 & 34 & 19.7 & 73 & 20.7 & 23 & 20.5 & 50 & 20.8 \\
\hline & 3 & 74 & 18.4 & 44 & 19.2 & 30 & 17.3 & 60 & 17.1 & 20 & 17.9 & 40 & 16.7 \\
\hline & 4 & 84 & 20.9 & 51 & 22.3 & 33 & 19.1 & 58 & 16.5 & 19 & 17.0 & 39 & 16.3 \\
\hline & 5 (high) & 67 & 16.7 & 42 & 18.3 & 25 & 14.5 & 42 & 11.9 & 13 & 11.6 & 29 & 12.1 \\
\hline
\end{tabular}

Number of family doctor visits in the past year 
Table 1 Characteristics of the adult and pediatric study population by case status (Continued)

\begin{tabular}{|c|c|c|c|c|c|c|c|c|c|c|c|c|}
\hline \multicolumn{13}{|l|}{ Total deprivation category ${ }^{\ddagger}$} \\
\hline 1 (low) & 71 & 17.7 & 38 & 16.6 & 33 & 19.1 & 77 & 21.9 & 30 & 26.8 & 47 & 19.6 \\
\hline 2 & 257 & 63.9 & 153 & 66.8 & 104 & 60.1 & 219 & 62.2 & 72 & 64.3 & 147 & 61.3 \\
\hline 3 (high) & 50 & 12.4 & 28 & 12.2 & 22 & 12.7 & 42 & 11.9 & 10 & 8.9 & 32 & 13.3 \\
\hline $\begin{array}{l}\text { Individuals living in a neighbourhood } \\
\text { with low employment rate }\end{array}$ & 88 & 21.9 & 53 & 23.1 & 35 & 20.2 & 57 & 16.2 & 15 & 13.4 & 42 & 17.5 \\
\hline $\begin{array}{l}\text { Individuals residing in a neighbourhood } \\
\text { with high proportion of low income }\end{array}$ & 100 & 24.9 & 56 & 24.5 & 44 & 25.4 & 74 & 21.0 & 13 & 11.6 & 61 & 25.4 \\
\hline High school or less education & 58 & 14.4 & 35 & 15.3 & 23 & 13.3 & 53 & 15.1 & 16 & 14.3 & 37 & 15.4 \\
\hline Post-secondary education completed & 261 & 64.9 & 153 & 66.8 & 108 & 62.4 & 250 & 71.0 & 77 & 68.8 & 173 & 72.1 \\
\hline Household density (median) ${ }^{\|}$ & & 1.0 & & 1.0 & & 1.0 & & 1.3 & & 1.2 & & 1.3 \\
\hline \multicolumn{13}{|l|}{ Children in household } \\
\hline 0 & 231 & 57.5 & 144 & 62.9 & 87 & 50.3 & $\mathrm{~N} / \mathrm{A}$ & & N/A & & $\mathrm{N} / \mathrm{A}$ & \\
\hline 1 & 170 & 42.3 & 84 & 36.7 & 86 & 49.7 & 247 & 70.2 & 79 & 70.5 & 168 & 70.0 \\
\hline 2 & $\mathrm{~N} / \mathrm{A}$ & & N/A & & N/A & & 79 & 22.4 & 25 & 22.3 & 54 & 22.5 \\
\hline 3 & $\mathrm{~N} / \mathrm{A}$ & & $\mathrm{N} / \mathrm{A}$ & & N/A & & 24 & 6.8 & 7 & 6.3 & 17 & 7.1 \\
\hline Receipt of 2008 seasonal vaccine & 156 & 38.8 & 83 & 36.2 & 73 & 42.2 & 108 & 30.7 & 25 & 22.3 & 83 & 34.6 \\
\hline Tested before June 11th, 2009 & 315 & 78.4 & 17 & 7.4 & 103 & 59.5 & 251 & 71.3 & 112 & 100.0 & 139 & 57.9 \\
\hline Healthcare provider" & 48 & 11.9 & 23 & 10.0 & 25 & 14.5 & N/A & & N/A & & $\mathrm{N} / \mathrm{A}$ & \\
\hline Resides in Toronto & 121 & 30.1 & 84 & 36.7 & 37 & 21.4 & 78 & 22.2 & 24 & 21.4 & 54 & 22.5 \\
\hline \multicolumn{13}{|l|}{ Immigrant category } \\
\hline Non-Immigrant & 251 & 62.4 & 148 & 64.6 & 103 & 59.5 & 316 & 89.8 & 106 & 94.6 & 210 & 87.5 \\
\hline Immigrant & $\mathrm{N} / \mathrm{A}$ & & $\mathrm{N} / \mathrm{A}$ & & N/A & & 36 & 10.2 & 6 & 5.4 & 30 & 12.5 \\
\hline Immigrant, settled for $0-5$ years & 24 & 6.0 & 9 & 3.9 & 15 & 8.7 & $\mathrm{~N} / \mathrm{A}$ & & N/A & & $\mathrm{N} / \mathrm{A}$ & \\
\hline Immigrant, settled for $>5$ & 121 & 30.1 & 67 & 29.3 & 54 & 31.2 & $\mathrm{~N} / \mathrm{A}$ & & N/A & & N/A & \\
\hline Hospitalized & 64 & 15.9 & 0 & 0 & 64 & 37.0 & 79 & 22.4 & 0 & 0 & 79 & 32.9 \\
\hline
\end{tabular}

*This was based on the question "People in Canada come from many different ethnic and racial backgrounds. I would like you to identify which ethnicity best describes you. You may choose more than one category." The ethnic groupings were based on the categories similar to Statistics Canada definitions. †Underlying medical conditions for adults was having at least one of the following: diabetes, cancer, heart disease, asthma, chronic obstructive pulmonary disease (COPD), immune disorder, liver disease, kidney or renal disease, splenectomy, sickle cell anemia, seizure disorder, leukemia, cystic fibrosis, or cerebral palsy. In children, underlying medical conditions was having either asthma or immune disorder.

${ }^{\ddagger}$ Material Deprivation was based on employment to population ratio, average income and proportion without high school diploma. Social deprivation was based on proportion of persons living alone; proportion separated, divorced or widowed; and proportion of single-parent families. Quintiles of material and social deprivation were created based on dissemination areas in Ontario, with a score of 1 representing low deprivation and 5 indicating high deprivation. The material and social deprivation were combined to form a total deprivation score, which was categorized as high, middle or low deprivation.

${ }^{\S}$ Low employment rate and High Proportion of Low Income are based on individuals residing in a dissemination area in Ontario. Individuals living in a neighbourhood in the bottom quintile of all dissemination areas for low employment/with high proportion of low income, based on our study population, were classified as being in the low employment rate/high proportion of low income categories.

"Calculated as the number of people in the household divided by the number of sleeping rooms in the household.

"Healthcare provider is defined as a doctor, nurse or another healthcare professional.

$\mathrm{N} / \mathrm{A}=$ Not applicable.

Cases were more likely to be South Asian (OR 2.92, 95\% CI 1.11-7.68), Black (OR 16.02, 95\% CI 2.85-89.92), or West Asian/Arab, Latin American, or Multi-racial (OR 3.09 95\% CI 1.06-9.00). The ORs for ethnic groups were higher for adults who resided outside Toronto compared to those who resided in Toronto (Table 4). This effect was seen for all ethnic groups, except East/Southeast Asian. This trend was also observed in children but both failed to reach statistical significance (results not shown). Testing date was controlled for in the multivariate model, however, since many of the controls were tested after June 11, we ran a sensitivity analyses restricting to only controls tested prior to June 11, and aside from increasing confidence intervals the parameter estimates for ethnicity were relatively unchanged.

\section{Discussion}

In this case-control study we found evidence of ethnic disparities in acquiring the 2009 pandemic H1N1 such that among adults lab-confirmed $\mathrm{pH} 1 \mathrm{~N} 1$ cases were 
Table 2 Unadjusted odds ratios for pH1N1 influenza acquisition for various potential risk factors in adults and children

\begin{tabular}{|c|c|c|c|c|}
\hline Variable & & $\begin{array}{l}\text { Adults } \\
\text { OR }(95 \% \mathrm{Cl})\end{array}$ & & $\begin{array}{l}\text { Children } \\
\text { OR }(95 \% \mathrm{Cl})\end{array}$ \\
\hline \multirow[t]{5}{*}{ Ethnicity* } & White & ref & & ref \\
\hline & East/Southeast Asian & $1.33(0.69-2.56)$ & & $2.39(1.14-5.01)$ \\
\hline & South Asian & $3.07(1.42-6.63)$ & & $1.72(0.86-3.45)$ \\
\hline & Black & $4.50(1.57-12.87)$ & & $4.38(1.62-11.84)$ \\
\hline & Other & $1.21(0.59-2.46)$ & & $2.84(1.33-6.08)$ \\
\hline \multirow[t]{4}{*}{ Age } & $18-34$ & ref & $<5$ & $0.45(0.26-0.79)$ \\
\hline & $35-49$ & $0.83(0.52-1.34)$ & $5-11$ & $1.39(0.79-2.43)$ \\
\hline & $50-64$ & $0.71(0.42-1.20)$ & $12-17$ & ref \\
\hline & $65+$ & $0.64(0.29-1.39)$ & & \\
\hline Gender (Female) & & $0.93(0.62-1.39)$ & & $0.90(0.55-1.47)$ \\
\hline \multirow[t]{3}{*}{ BMI class } & $\|(18.5 \leq \mathrm{BMI}<25)$ & ref & & ref \\
\hline & III $(25 \leq \mathrm{BMI}<30)$ & $1.23(0.77-1.96)$ & & $1.48(0.61-3.60)$ \\
\hline & IV (BMI $\geq 30)$ & $1.31(0.76-2.26)$ & & \\
\hline Current smoker & & $0.68(0.43-1.07)$ & & $0.96(0.91-1.02)$ \\
\hline \multirow{3}{*}{$\begin{array}{l}\text { Number of visits to family doctor } \\
\text { in the past year }\end{array}$} & $\operatorname{Low}(<=1)$ & $0.90(0.53-1.54)$ & & $1.49(0.83-2.69)$ \\
\hline & Moderate (2-6) & ref & & ref \\
\hline & High $(>6)$ & $1.81(1.07-3.07)$ & & $1.07(0.61-1.90)$ \\
\hline Underlying medical conditions $^{\dagger}$ & & $1.51(0.93-2.44)$ & & $0.81(0.44-1.48)$ \\
\hline \multirow[t]{5}{*}{ Material deprivation $^{\ddagger}$} & 1 (low) & ref & & ref \\
\hline & 2 & $1.76(0.96-3.19)$ & & $1.07(0.54-2.10)$ \\
\hline & 3 & $1.49(0.78-2.85)$ & & $1.11(0.55-2.22)$ \\
\hline & 4 & $2.11(1.08-4.11)$ & & $1.55(0.76-3.17)$ \\
\hline & 5 (high) & $1.23(0.65-2.31)$ & & $1.22(0.58-2.56)$ \\
\hline \multirow[t]{5}{*}{ Social deprivation ${ }^{\ddagger}$} & 1 (low) & ref & & ref \\
\hline & 2 & $1.23(0.65-2.34)$ & & $1.18(0.63-2.23)$ \\
\hline & 3 & $0.87(0.46-1.63)$ & & $1.09(0.56-2.13)$ \\
\hline & 4 & $0.82(0.45-1.52)$ & & $1.12(0.57-2.20)$ \\
\hline & 5 (high) & $0.76(0.39-1.46)$ & & $1.21(0.56-2.61)$ \\
\hline \multirow[t]{3}{*}{ Total deprivation category ${ }^{\ddagger}$} & 1 (low) & ref & & ref \\
\hline & 2 & $0.78(0.46-1.33)$ & & $1.30(0.76-2.23)$ \\
\hline & 3 (high) & $0.91(0.44-1.87)$ & & $2.04(0.88-4.75)$ \\
\hline $\begin{array}{l}\text { Individuals living in a neighbourhood } \\
\text { with low employment rate }\end{array}$ & & $0.84(0.52-1.36)$ & & $1.37(0.73-2.60)$ \\
\hline $\begin{array}{l}\text { Individuals residing in a neighbourhood } \\
\text { with a high proportion of low income }\end{array}$ & & $1.05(0.67-1.66)$ & & $2.60(1.36-4.96)$ \\
\hline High school or less education & & $0.85(0.48-1.50)$ & & $1.09(0.58-2.06)$ \\
\hline Post-secondary school completion & & $0.82(0.54-1.24)$ & & $1.21(0.74-1.98)$ \\
\hline Household density" & & $1.26(0.84-1.87)$ & & $1.81(0.95-3.44)$ \\
\hline \multirow[t]{3}{*}{ Children in household } & & $1.70(1.13-2.53)$ & 1 & ref \\
\hline & & & 2 & $1.02(0.59-1.75)$ \\
\hline & & & $>3$ & $1.14(0.46-2.87)$ \\
\hline Receipt of 2008 seasonal vaccine & & $1.25(0.84-1.88)$ & & $1.96(1.16-3.31)$ \\
\hline Tested prior to June 11th, 2009 & & $0.12(0.07-0.21)$ & & N/A \\
\hline Healthcare provider" & & $1.51(0.83-2.77)$ & & N/A \\
\hline
\end{tabular}


Table 2 Unadjusted odds ratios for pH1N1 influenza acquisition for various potential risk factors in adults and children (Continued)

\begin{tabular}{|c|c|c|}
\hline Toronto & $0.47(0.30-0.74)$ & $1.07(0.62-1.83)$ \\
\hline \multicolumn{3}{|l|}{ Immigrant category } \\
\hline Non-Immigrant & ref & ref \\
\hline Immigrant & N/A & $2.52(1.02-6.25)$ \\
\hline Immigrant, Settled for 0-5 years & $2.40(1.01-5.68)$ & N/A \\
\hline Immigrant, Settled for $>5$ & $1.16(0.75-1.80)$ & N/A \\
\hline
\end{tabular}

*This was based on the question "People in Canada come from many different ethnic and racial backgrounds. I would like you to identify which ethnicity best describes you. You may choose more than one category." The ethnic groupings were based on the categories similar to Statistics Canada definitions.

'Underlying medical conditions for adults was having at least one of the following: diabetes, cancer, heart disease, asthma, chronic obstructive pulmonary disease (COPD), immune disorder, liver disease, kidney or renal disease, splenectomy, sickle cell anemia, seizure disorder, leukemia, cystic fibrosis, or cerebral palsy. In children, underlying medical conditions was having either asthma or immune disorder.

${ }^{\ddagger}$ Material Deprivation was based on employment to population ratio, average income and proportion without high school diploma. Social deprivation was based on proportion of persons living alone; proportion separated, divorced or widowed; and proportion of single-parent families. Quintiles of material and social deprivation were created based on dissemination areas in Ontario, with a score of 1 representing low deprivation and 5 indicating high deprivation. The material and social deprivation were combined to form a total deprivation score, which was categorized as high, middle or low deprivation.

sow employment rate and High Proportion of Low Income are based on individuals residing in a dissemination area in Ontario. Individuals living in a neighbourhood in the bottom quintile of all dissemination areas for low employment/with high proportion of low income, based on our study population, were classified as being in the low employment rate/high proportion of low income categories.

"Calculated as the number of people in the household divided by the number of sleeping rooms in the household.

"Healthcare provider is defined as a doctor, nurse or another healthcare professional.

$\mathrm{N} / \mathrm{A}=$ Not applicable.

more likely to be of East/Southeast Asian, South Asian and Black ethnicity compared to test-negative controls. This association persisted after controlling for several important confounders, including individual and ecological socioeconomic measures and clinical risk factors, and under a variety of restrictions imposed as part of a sensitivity analysis. Among children, not all ethnic disparities seen in adults were detected, however consistent with adults, pediatric cases were more likely to be classified as Black compared to other ethnic groups after controlling for confounders.

Previous studies have found ethnic discrepancies when looking at the distribution of pH1N1 illnesses. In Utah, U.S., it was reported that $29.5 \%$ of $\mathrm{pH} 1 \mathrm{~N} 1$ hospitalized cases were minorities (those not classified as non-Hispanic Whites), significantly greater than the mean of $22 \%$ of hospitalized cases that were minorities during the previous three influenza seasons [9]. The majority of studies have looked at hospitalization rates due to $\mathrm{pH} 1 \mathrm{~N} 1$ and ethnic disparities. For example, in Chicago, U.S., Asian/Pacific Islanders, the non-Hispanic Black group, and the Hispanic group had higher rates of hospitalization due to $\mathrm{pH} 1 \mathrm{~N} 1$ compared to the non-Hispanic White group [10]. Also, in Wisconsin, U.S., it was reported that the groups classified as Black, Hispanic, and Asian had several-fold higher hospitalization than the non-Hispanic White group due to pH1N1 [11]. Similar findings have also been reported in the United Kingdom [23]. Social factors may explain the ethnic disparities seen in this and other studies, which may operate through a variety of mechanisms. Social factors such as crowding, use of public transit, and ability to keep children away from other groups of children during school or day-care centre closures during a pandemic can play a role in increasing exposure risk [16]. A study in the U.S. compared social risk factors, including social distancing across ethnicities, and found that those identifying as Black and Hispanic (both Spanish and English speaking) found it more difficult to avoid public transportation than nonHispanic White [17]. Also, those identifying as Black and Spanish-speaking Hispanic reported greater challenges to finding childcare that separated their children from other children, compared to those identifying as nonHispanic White. There may also be differential access to information regarding the risks associated with influenza as well as preventive measures. For example, we have evidence from seasonal vaccination programs that certain ethnic groups are less likely to receive seasonal influenza vaccines $[24,25]$.

This study does have a few limitations. First, we were somewhat limited in sample size for certain ethnic groups, resulting in wide confidence intervals observed for adults and children who identified their ethnicity as Black and South Asian. Including all variables in the multivariate model did slightly increase the width of the confidence intervals, however, the variables included were all important confounders and thus failing to control for these variables would produce confounded results. In addition, most of the variables are based on self-report and thus are susceptible to misclassification. Healthcare seeking behaviour was represented by number of primary care physician visits in the last 12 months. However, healthcare seeking behaviour could also be measured by the resources and services that are available to ethnic groups within their own communities. It is important to note that all individuals in this study 
Table 3 Odds ratios from multivariate logistic regression models for pH1N1 illness acquisition and ethnicity under various sensitivity analyses

\begin{tabular}{|c|c|c|}
\hline Ethnic group* & $\begin{array}{c}\text { Adults } \\
\text { Adjusted OR }(95 \% \mathrm{Cl})^{\dagger}\end{array}$ & $\begin{array}{r}\text { Children } \\
\text { Adjusted OR (95 }\end{array}$ \\
\hline \multicolumn{3}{|l|}{$\begin{array}{l}\text { Restricted to those with symptoms and those tested for } \\
\text { reasons other than travel to Mexico (primary analysis) }\end{array}$} \\
\hline White & ref & ref \\
\hline East/Southeast Asian & $2.59(1.02-6.57)$ & $1.96(0.82-4.66)$ \\
\hline South Asian & $6.22(2.01-19.24)$ & $1.88(0.80-4.41)$ \\
\hline Black & $9.72(2.29-41.27)$ & $6.44(1.83-22.59)$ \\
\hline Other & $2.00(0.74-5.42)$ & $2.06(0.83-5.11)$ \\
\hline
\end{tabular}

Individuals tested because of travel to Mexico added

White

East/Southeast Asian

South Asian

Black

Other

Those not presenting with symptoms are included

White East/Southeast Asian

South Asian

Black

Other

No restrictions

White

East/Southeast Asian

South Asian

Black

Other

Heart disease and diabetes added independently

of other underlying medical conditions

$$
\begin{array}{r}
\text { White } \\
\text { East/Southeast Asian } \\
\text { South Asian } \\
\text { Black } \\
\text { Other }
\end{array}
$$

Without risk factors

White

East/Southeast Asian

South Asian

Black

Other ref

$2.99(1.20-7.45)$

$7.34(2.42-22.28)$

$10.93(2.61-45.73)$

$2.24(0.88-5.70)$

ref

$2.57(1.06-6.23)$

6.03 (2.21-16.44)

$10.34(2.58-41.46)$

$1.67(0.70-3.99)$

ref

2.96 (1.24-7.05)

7.42 (2.79-19.74)

$11.28(2.85-44.60)$

$1.79(0.78-4.08)$

ref

$2.56(0.99-6.64)$

6.55 (1.99-21.57)

$10.19(2.35-44.22)$

$1.34(0.46-3.90)$

ref

2.63 (0.91-7.59)

ref

10.34 (2.39-44.80)

$2.48(0.92-6.64)$

$2.92(1.11-7.68)$

11.90 (2.30-61.65)

$16.02(2.85-89.92)$

1.69 (0.54-5.30) ref

2.01 (0.85-4.73)

$1.84(0.80-4.24)$

$6.45(1.86-22.44)$

$1.70(0.73-3.97)$

ref

$1.92(0.84-4.38)$

$1.83(0.81-4.14)$

$5.44(1.72-17.24)$

$2.28(0.95-5.45)$

ref

1.99 (0.88-4.50)

$1.82(0.82-4.06)$

5.62 (1.78-17.71)

$1.80(0.81-4.01)$ 
Table 3 Odds ratios from multivariate logistic regression models for pH1N1 illness acquisition and ethnicity under various sensitivity analyses (Continued)

Tested prior to June 11th, 2009

$\begin{array}{rll}\text { White } & \text { ref } & \text { ref } \\ \text { East/Southeast Asian } & 2.66(1.01-7.02) & 2.90(1.10-7.64) \\ \text { South Asian } & 6.97(2.07-23.50) & 1.82(0.68-4.87) \\ \text { Black } & 8.18(1.85-36.22) & 7.21(1.72-30.21) \\ \text { Other } & 2.05(0.70-6.05) & 2.34(0.82-6.71)\end{array}$

*This was based on the question "People in Canada come from many different ethnic and racial backgrounds. I would like you to identify which ethnicity best describes you. You may choose more than one category." The ethnic groupings were based on the categories similar to Statistics Canada definitions.

${ }^{\dagger}$ For adults, all models were adjusted for age, sex, children in household, material deprivation, chronic conditions, receipt of 2008 seasonal vaccine, tested prior to June 11 th, 2009, residing in Toronto, length of stay in Canada.

${ }^{\ddagger}$ For children, all models were adjusted for age, sex, total deprivation, receipt of 2008 seasonal vaccine, high proportion of neighbourhood with low income, material deprivation, post-secondary education, chronic condition, residence in Toronto.

sought care, thus minimizing the bias that access would have on the results. Another limitation is that a few of the variables were not available at the individual level, such as household income and employment, which are important confounders to consider for studying this relationship. Ecological-level variables were used to assess impact of income based on prevalence of low income among total persons in household within a dissemination area. It should also be noted that these findings were specific to our study, and they may be different for other studies with different ethnic compositions.

Table 4 A multivariate logistic regression model for pH1N1 illness acquisition in adults and ethnicity, stratified by Toronto residence

\begin{tabular}{ll}
\hline Ethnic group* & $\begin{array}{l}\text { Wave } \mathbf{1} \\
\text { OR }(\mathbf{9 5} \% \mathbf{C l})^{\dagger}\end{array}$ \\
\hline $\begin{array}{l}\text { Not Residing in Toronto } \\
\text { White }\end{array}$ & ref \\
East/Southeast Asian & $1.86(0.57-6.08)$ \\
South Asian & $9.95(2.17-45.59)$ \\
Black & $14.61(1.49-143.36)$ \\
Other & $2.26(0.68-7.53)$ \\
Residing in Toronto & \\
White & ref \\
East/Southeast Asian & $6.80(1.02-45.51)$ \\
South Asian & $2.32(0.29-18.79)$ \\
Black & $4.20(0.38-46.46)$ \\
Other & $1.50(0.17-13.48)$ \\
\hline
\end{tabular}

*This was based on the question "People in Canada come from many different ethnic and racial backgrounds. I would like you to identify which ethnicity best describes you. You may choose more than one category." The ethnic groupings were based on the categories similar to Statistics Canada definitions.

${ }^{\dagger}$ For adults, all models were adjusted for age, sex, children in household, material deprivation, chronic conditions, receipt of 2008 seasonal vaccine, tested prior to June 11 th, 2009, length of stay in Canada

\section{Conclusions}

The purpose of this study was to determine whether there are ethnic disparities in acquiring the 2009 pandemic $\mathrm{H} 1 \mathrm{~N} 1$, and this study did find evidence for such disparities. Identifying ethnic differences in infectious disease risk is critical to understanding how best to reduce any excess burden experienced by these populations. To minimize risk in these ethnic groups, further insight needs to be gained as to whether these findings are a result of social or biological factors, or both. The understanding of the origin of these disparities in acquiring $\mathrm{pH} 1 \mathrm{~N} 1$ can help us to promote and plan interventions accordingly to reduce the burden of illness among ethnic groups.

Competing interests

The authors declare that they have no competing interests.

\section{Authors' contributions}

$L R$ and NC were responsible for conception and design. DN and LR performed the statistical analyses. All of the authors contributed in the interpretation and the discussion of the results. DN wrote the first draft of the paper. All of the authors critically reviewed and contributed to the final draft. All authors read and approved the final manuscript.

\section{Acknowledgements}

The study was funded by the Ontario Ministry of Health and Long-Term Care. The views expressed here are those of the authors and not necessarily those of the funding agency. The funding agency had no role in the data collection or in the writing of this paper. The guarantors accept full responsibility for the conduct of the study, had access to the data, and controlled the decision to publish.

\section{Author details}

'Department of Public Health Sciences, Public Health Ontario, 480 University Avenue, Suite 300, Toronto, Ontario M5G 1 V2, Canada. ${ }^{2}$ Dalla Lana School of Public Health, University of Toronto, 155 College Street, Toronto, Ontario M5T 3 M7, Canada. ${ }^{3}$ Institute for Clinical Evaluate Sciences, 2075 Bayview Avenue, Toronto, Ontario M4N 3 M5, Canada. ${ }^{4}$ Department of Family and Community Medicine, University of Toronto, 500 University Avenue, Toronto, Ontario M5G 1 V7, Canada.

Received: 2 September 2013 Accepted: 20 February 2014 Published: 1 March 2014 


\section{References}

1. Statistics Canada: Canada's Ethnocultural Mosaic, 2006 Census. http://www12.statcan.ca/census-recensement/2006/as-sa/97-562/pdf/97562-XIE2006001.pdf.

2. Anand SS, Yusuf S, Vuksan V, Devanesen S, Teo KK, Montague PA, Kelemen L, Yi C, Lonn E, Gerstein H, Hegele RA, McQueen M: Differences in risk factors, atherosclerosis, and cardiovascular disease between ethnic groups in Canada: the Study of Health Assessment and Risk in Ethnic groups (SHARE). Lancet 2000, 356(9226):279-284.

3. Manuel DG, Schultz SE: Diabetes Health Status and Risk Factors. In Diabetes in Ontario: An ICES Practice Atlas. Edited by Hux J, Booth G, Laupacis A. Toronto, Ontario: Institute for Clinical Evaluative Sciences; 2002:4.77-4.93.

4. Tremblay MS, Pérez CS, Ardern Cl, Bryan SN, Katzmarzyk PT: Obesity, overweight and ethnicity. Health Rep 2005, 16(4):23-34.

5. Yousey-Hindes KM, Hadler JL: Neighborhood Socioeconomic Status and Influenza Hospitalizations Among Children: New Haven County, Connecticut, 2003-2010. Am J Public Health 2011, 101(9):1785-1789.

6. Lowcock EC, Rosella LC, Foisy J, McGeer AJ, Crowcroft NS: The Social Determinants of Health and Pandemic H1N1 2009 Influenza Severity. Am J Public Health 2012, 102(8):e51-e58.

7. Rutter PD, Mytton OT, Mak M, Donaldson L: Socio-economic disparities in mortality due to pandemic influenza in England. Int J Public Health 2012, 57(4):745-750

8. Kumar S, Quinn SC, Kim KH, Daniel LH, Freimuth VS: The impact of workplace policies and other social factors on self-reported influenza-like illness incidence during the 2009 H1N1 pandmic. Am J Public Health 2012, 102(1):134-140.

9. Centres for Disease Control and Prevention: Severe Illness from 2009 Pandemic Influenza A (H1N1) -Utah, 2009-10 Influenza Season. Morb Mortal Wkly Rep 2011, 60(38):1310-1314.

10. Centers for Disease Control and Prevention: 2009 Pandemic influenza a (H1N1) virus infections - Chicago, Illinois, April-July 2009. MMWR Morb Mortal Wkly Rep 2009, 58(33):913-918.

11. Chitnis AS, Truelove SA, Druckenmiller JK, Heffernan RT, Davis JP: Epidemiologic and clinical features among patients hospitalized in Wisconsin with $2009 \mathrm{H} 1 \mathrm{~N} 1$ influenza A virus infections, April to August 2009. Wis Med J 2010, 109(4):201-208.

12. Zarychanski R, Stuart TL, Kumar A, Doucette S, Elliott L, Kettner J, Plummer F Correlates of severe disease in patients with 2009 pandemic influenza (H1N1) virus infection. CMAJ 2010, 182(3):257-264.

13. Helferty M, Vachon J, Tarasuk J, Rodin R, Spika J, Pelletier L: Incidence of hospital admissions and severe outcomes during the first and second waves of pandemic (H1N1) 2009. CMAJ 2010, 182(18):1981-1987.

14. Campbell A, Rodin R, Kropp R, Mao Y, Hong Z, Vachon J, Spika J, Pelletier L: Risk of severe outcomes among patients admitted to hospital with pandemic (H1N1) influenza. CMAJ 2010, 182(4):349-355.

15. Public Health Agency of Canada: Frequently Asked Questions - Influenza. http://www.phac-aspc.gc.ca/influenza/influenza-faq-eng.php\#h.

16. Blumenshine $P$, Reingold A, Egerter S, Mockenhaupt R, Braveman P, Marks J: Pandemic influenza planning in the united states from a health disparities perspective. Emerg Infect Dis 2008, 14(5):709-715.

17. Quinn S, Kumar S, Freimuth V, Musa D, Casteneda-Angarita N, Kidwell K: Racial disparities in exposure, susceptibility, and access to health care in the US H1N1 influenza pandemic. Am J Public Health 2011, 101(2):285-293.

18. Orenstein WA, Bernier RH, Dondero TJ, Hinman AR, Marks JS, Bart KJ, Sirotkin B: Field evaluation of vaccine efficacy. Bull WHO 1985, 63:1055-1068.

19. Ontario Ministry of Health and Long-Term Care: Important health notice - June 11, 2009. http://www.health.gov.on.ca/en/pro/programs/ emb/health_notices/ihn_20090611.pdf.

20. Pampalon R, Hamel D, Gamache P, Raymond G: A deprivation index for health planning in Canada. Chronic Dis Can 2009, 29(4):178-181.

21. Institut national de santé publique du Québec: Indice de défavorisation, Canada. 2006. http://www.inspq.qc.ca/santescope/indicedefavo.asp? NolndD $=9$.

22. Hosmer D, Lemeshow S: Chapter 4: Model Building Strategies for Logistic Regression. In Applied Logistic Regression. 2nd edition. New York: John Wiley; 2000.

23. Nguyen-Van-Tam JS, Openshaw PJ, Hashim A, Gadd EM, Lim WS, Semple MG, Read RC, Taylor BL, Brett SJ, McMenamin J, Enstone JE, Armstrong C, Nicholson KG, Influenza Clinical Information Network (FLU-CIN): Risk factors for hospitalisation and poor outcome with pandemic A/H1N1 influenza: United Kingdom first wave (May-September 2009). Thorax 2010, 65(7):645-651.

24. Quach S, Hamid JS, Pereira JA, Heidebrecht CL, Deeks SL, Crowcroft NS, Quan SD, Brien S, Kwong JC: Ethnic disparities in influenza immunization in Canada. CMAJ 2012, 184(15):1673-1681

25. Uscher-Pines L, Maurer J, Harris KM: Racial and ethnic disparities in uptake and location of vaccination for 2009-H1N1 and seasonal influenza. Am J Public Health 2011, 101(7):1252-1255.

doi:10.1186/1471-2458-14-214

Cite this article as: Navaranjan et al: Ethnic disparities in acquiring 2009 pandemic H1N1 influenza: a case-control study. BMC Public Health 2014 14:214.

\section{Submit your next manuscript to BioMed Central and take full advantage of:}

- Convenient online submission

- Thorough peer review

- No space constraints or color figure charges

- Immediate publication on acceptance

- Inclusion in PubMed, CAS, Scopus and Google Scholar

- Research which is freely available for redistribution

Submit your manuscript at www.biomedcentral.com/submit
Ciomed Central 